\title{
Remote Electronic Control of DNA-Based Reactions and Nanostructure Assembly
}

\author{
Alessia Amodio, ${ }^{\dagger, \S}$ Erica Del Grosso, ${ }^{\dagger, \S}$ Alessandra Troina, ${ }^{\dagger}$ Ernesto Placidi, ${ }^{\ddagger}$ and Francesco Ricci* ${ }^{\dagger} \dagger$ (1) \\ ${ }^{\dagger}$ Department of Chemical Science and Technologies, University of Rome, Tor Vergata, Via della Ricerca Scientifica, 00133, Rome, \\ Italy \\ ${ }^{\ddagger}$ Istituto di Struttura della Materia (ISM-CNR), via Fosso del Cavaliere 100, 00133 Rome, Italy
}

Supporting Information

ABSTRACT: The use of synthetic DNA to design and build molecular machines and well-defined structures at the nanoscale has greatly impacted the field of nanotechnology. Here we expand the current toolkit in this field by demonstrating an efficient, quantitative, and versatile approach that allows us to remotely control DNA-based reactions and DNA nanostructure self-assembly using electronic inputs. To do so we have deposited onto the surface of disposable chips different DNA input strands that upon the application of a cathodic potential can be desorbed in a remote and controlled way and trigger DNA-based reactions and DNA nanostructure self-assembly. We demonstrate that this effect is specific and versatile and allows the orthogonal control of multiple reactions and multiple structures in the same solution. Moreover, the strategy is highly tunable and can be finely modulated by varying the cathodic potential, the period of applied potential, and the density of the DNA strand on the chip surface. Our approach thus represents a versatile way to remotely control DNA-based circuits and nanostructure assembly and can allow new possible applications of DNA-based nanotools.

KEYWORDS: DNA nanotechnology, nucleic acids, self-assembly, DNA origami, electronic
S ynthetic DNA can be used to design and build molecular machines and well-defined structures at the nanoscale with potential applications in the field of diagnostic and drugdelivery. ${ }^{1-7}$ The high programmability and easy-to-predict thermodynamic and kinetic of DNA make it a perfect candidate material to build structures at the nanoscale in an affordable and straightforward way highly simplifying both the design and construction phase. $^{8-11}$ A variety of two-dimensional (2D) and three-dimensional (3D) ${ }^{12-19}$ structures have been reported to date that are not only highly precise over the nanoscale but could also be designed to perform multiple tasks in response to specific inputs. ${ }^{20-23}$ Most of these examples rely on very simple and highly programmable DNA-based reactions. The most commonly used of these reactions is the toehold strand displacement reaction where an "input" DNA strand can invade a target duplex and lead to the displacement of a singlestranded DNA sequence. This reaction is highly controllable and sequence specific, could be performed under isothermal conditions, and the determinants in terms of kinetic, specificity and selectivity have been thoroughly investigated. ${ }^{24-26}$

Strand displacement reactions can be used to control the assembly $^{27-31}$ and disassembly ${ }^{32,33}$ of DNA-based nanostructures in a versatile and reversible way and to actuate DNAbased nanomachines with high accuracy and precision. ${ }^{24,34-36}$ By using different strategies it is also possible to make DNA strand displacement reactions and thus make assembly and actuation of DNA-based nanostructures a process controllable

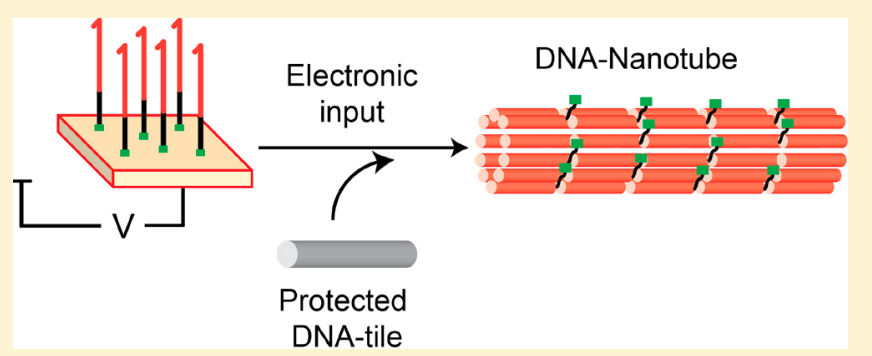

through molecular inputs other than nucleic acid strands such as $\mathrm{pH},{ }^{37-41}$ small molecules, ${ }^{42-45}$ enzymes, ${ }^{46}$ metal ions ${ }^{47}$ and temperature. ${ }^{48}$ In order to widen the applicability of these devices, however, it would be ideal to control the construction and actuation of such molecular structures and machines without the addition of exogenous reagents. The possibility to remotely control DNA strand displacement reactions and DNA nanostructure self-assembly would in fact represent an important step toward the possible applications of such devices in real settings.

Recently, several groups have demonstrated the possibility of using DNA-modified strands containing light-sensitive bases to employ light as an external input and remotely control DNA nanostructure assembly and actuation. ${ }^{49-53}$ Although this approach is highly versatile and advantageous, it also presents several limitations. First, the need for modified bases could impact the overall cost and versatility of the approach and might ultimately represent a challenge from a synthetic point of view. Second, using light as an input does not easily allow one to quantitatively and finely control the assembly and actuation of the nanodevices. Finally, the type of actuation provided by light-sensitive modified DNA bases, such as azobenzenemodified oligonucleotides, ${ }^{49,52,53}$ is usually limited to cis-to-

Received: January 13, 2018

Revised: $\quad$ March 26, 2018

Published: April 2, 2018 
a

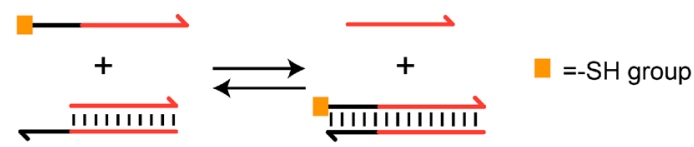

b
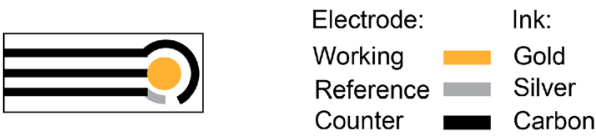

C
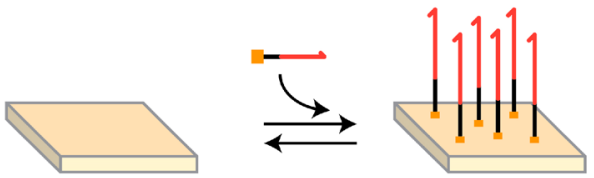

d
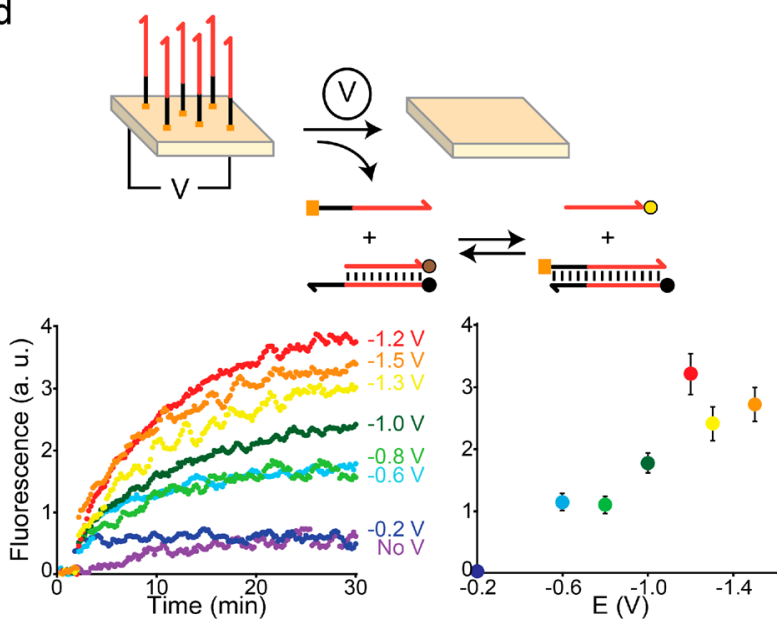

Figure 1. Remote electronic control of toehold DNA strand displacement reaction. A DNA input strand modified with a thiol group (a) supports spontaneous adsorption onto the gold surface of a screen printed disposable chip $(b, c)$. A cathodic potential applied onto the electrode surface (d) allows the release of the input strand from the chip surface in solution, thus triggering the strand displacement reaction. The effect can be modulated by varying the applied cathodic potential (d, bottom). Here we have employed an input DNA strand, containing a 7-base toehold portion and a 20-base invading domain. The experiments were performed at $25{ }^{\circ} \mathrm{C}$ in a $100 \mu \mathrm{L}$ solution of TAE $1 \times$ buffer $+15 \mathrm{mM} \mathrm{MgCl}_{2} \mathrm{pH} 7.0$, containing $10 \mathrm{nM}$ of target duplex labeled with a fluorophore/quencher pair. This solution (100 $\mu \mathrm{L}$ ) containing the reporter complex was placed onto the chip surface and cathodic potentials from -1.5 to $-0.2 \mathrm{~V}$ vs $\mathrm{Ag} / \mathrm{AgCl}$ were applied for a total period of $30 \mathrm{~s}$ after which the solution was immediately transferred to a quartz cuvette for time-course fluorescence measurement. The values shown here and in the following figures represent averages of three independent measurements; error bars reflect standard deviations.

trans transition making it difficult to orthogonally control more than a single process in the same solution.

Motivated by the above considerations, here we propose the use of electronic inputs applied at a heterogeneous surface as a new way to gain control over nucleic acid reactions occurring in solution. Our strategy is based on previous observations regarding DNA-based electrochemical sensors that have demonstrated the possibility of using cathodic potential inputs to release DNA strands from electrode surfaces in a controlled way. ${ }^{54-60}$ Using a similar approach, we aim to achieve an efficient, quantitative, and versatile approach that allows us to

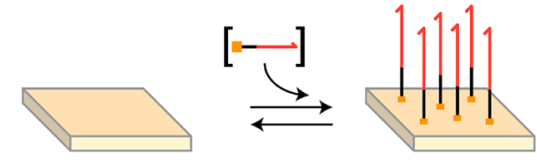

b
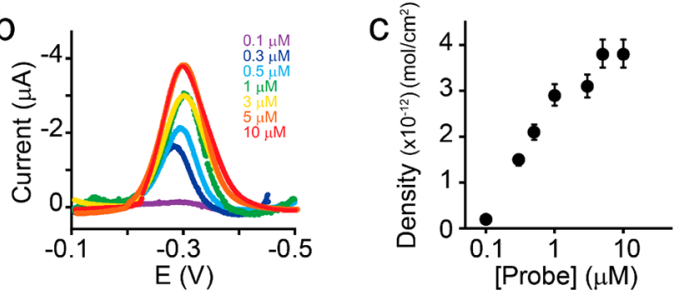

d
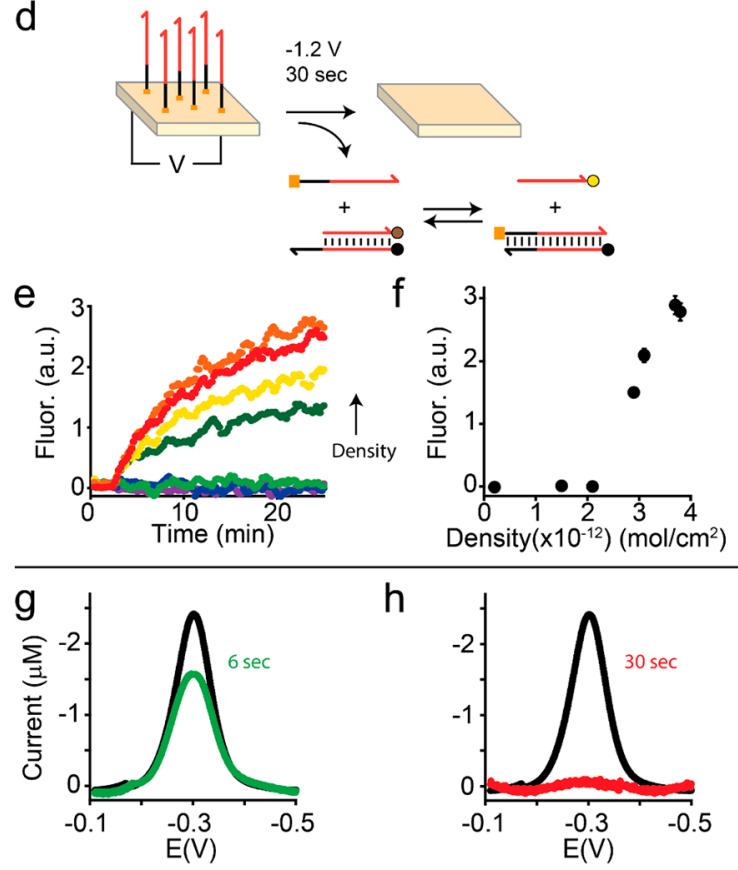

$\mathrm{h}$

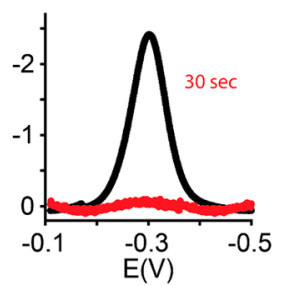

i
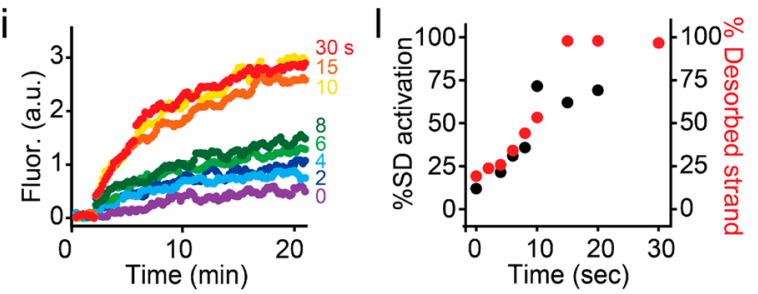

Figure 2. Modulation of toehold DNA strand displacement reaction through remote electronic control. The density of the input strand on the chip surface can be modulated by varying the DNA input strand concentration used during the deposition step (a). Shown are the square wave voltammetry (SWV) signals (b) and density values (c) obtained with a methylene-blue tagged input strand. Different densities provide different activation profile of the strand displacement reaction $(\mathrm{d}-\mathrm{f})$. Similarly, by varying the period of applied potential on a high-density chip we can modulate strand displacement activation. Shown are two examples of SWV signals before and after potential application for $6(\mathrm{~g})$ and $30(\mathrm{~h})$ seconds that demonstrate different degree of input strand desorption corresponding to different degree of strand displacement activation (i-1). Here we have employed the same system shown in Figure 1. The experiments were performed at $25^{\circ} \mathrm{C}$ in a $100 \mu \mathrm{L}$ solution of TAE $1 \times$ buffer $+15 \mathrm{mM} \mathrm{MgCl} 2 \mathrm{pH} 7.0$, containing $10 \mathrm{nM}$ of duplex target complex. For panels e and $\mathrm{f}$, the applied potential was $-1.2 \mathrm{~V}$ vs $\mathrm{Ag} / \mathrm{AgCl}$ for a total period of $30 \mathrm{~s}$. For panels $\mathrm{g}-\mathrm{i}$, the concentration of input strand used during the deposition step was $10 \mu \mathrm{M}$ and a fixed applied potential of $-1.2 \mathrm{~V}$ vs $\mathrm{Ag} / \mathrm{AgCl}$ was applied for different periods. 


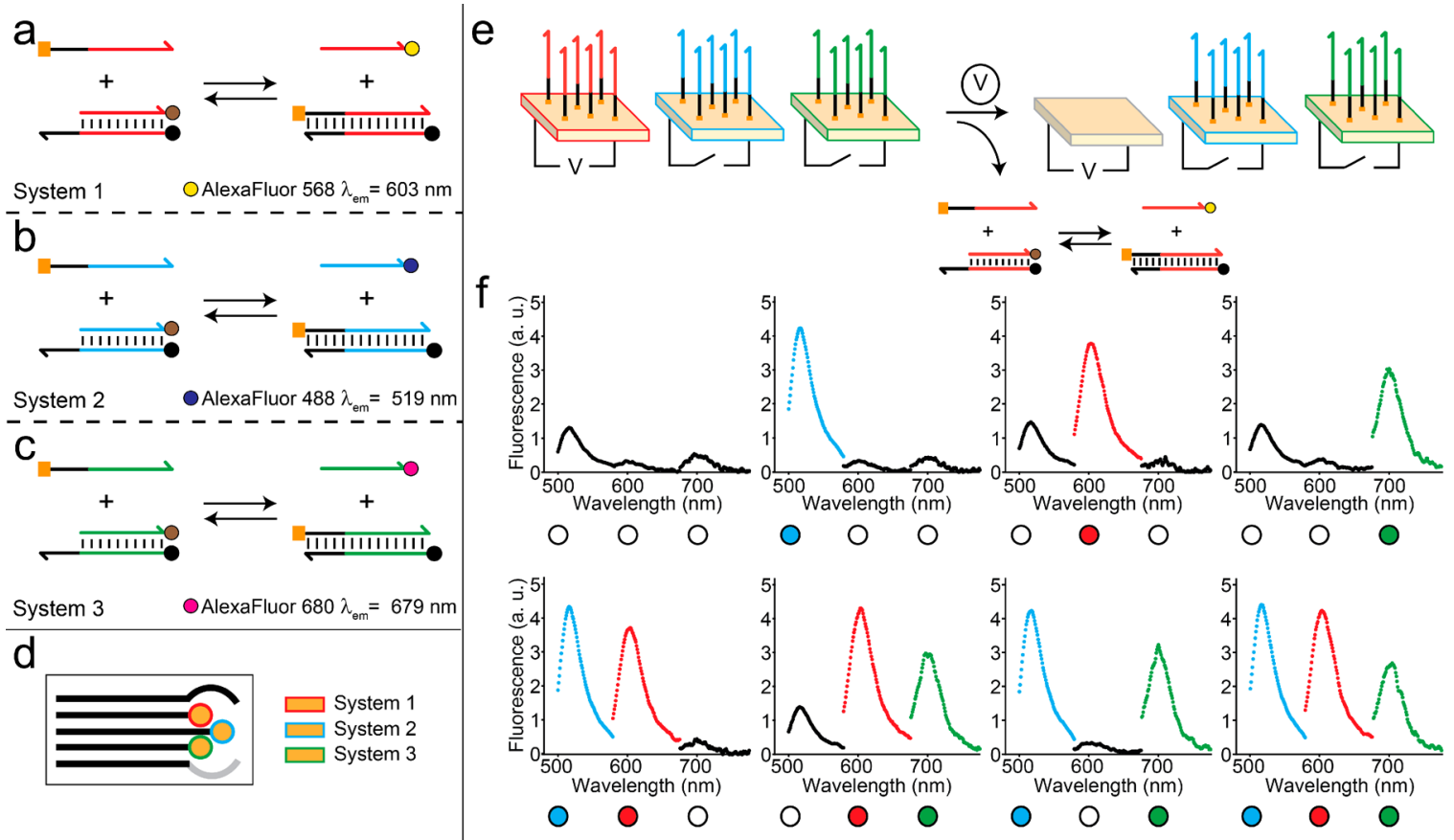

Figure 3. Orthogonal electronic control of toehold DNA strand displacement reactions. Schematics of three strand displacement systems each labeled with a different fluorophore $(a-c)$. Each input strand is deposited onto a single surface of a three-electrode chip (d) and can be selectively activated by cathodic applied potential (e). Fluorescence signals of the three systems obtained by applying the cathodic potential in different combinations (f). Filled and blank circles are used to identify the electrode at which the potential was applied in each different combination. The experiments were performed at $25{ }^{\circ} \mathrm{C}$ in a $100 \mu \mathrm{L}$ solution of TAE $1 \times$ buffer $+15 \mathrm{mM} \mathrm{MgCl}_{2} \mathrm{pH} 7.0$, containing $10 \mathrm{nM}$ of each duplex target complex. The concentration of each input strand used during the deposition step was $10 \mu \mathrm{M}$ and a fixed applied potential of $-1.2 \mathrm{~V}$ vs $\mathrm{Ag} / \mathrm{AgCl}$ was applied for $30 \mathrm{~s}$.

remotely and orthogonally control DNA strand displacement reactions and DNA nanostructure self-assembly. To demonstrate this, we first have designed an input DNA strand, containing a 7-base toehold portion and a 20-base invading domain, capable of inducing a conventional strand displacement reaction with a target duplex DNA (Figure 1a). Such input DNA strand is modified at one end $\left(3^{\prime}\right)$ with a thiol group which allows the ready and spontaneous deposition onto a gold electrode surface of a screen printed disposable chip (Figure 1b) through gold-thiol reaction (Figure 1c). By applying a fixed cathodic potential to such chip surface, it is possible to trigger the desorption of the input strand in solution and thus remotely control the activation of the strand displacement reaction (Figure 1d).

We first demonstrate that strand displacement reaction can be quantitatively modulated by varying the applied cathodic potential. For example, by applying a potential more negative than $-1.2 \mathrm{~V}$ ( $\mathrm{vs} \mathrm{Ag} / \mathrm{AgCl}$ ) we observe maximum desorption of the input strand from the chip surface and thus optimal strand displacement activation (Figure 1d). For potentials comprised between -1.2 and $-0.8 \mathrm{~V}$, intermediate activation is instead observed, whereas no significant desorption at applied potentials higher than $-0.6 \mathrm{~V}$ can be achieved (Figure 1d). Similarly, no strand displacement activation is observed in the absence of applied potential (Figure 1d), even after longer incubation periods (i.e., $60 \mathrm{~min}$, see Figure S1). This is likely due to the fact that the toehold domain responsible to start the strand displacement reaction is well hidden into the high density self-assembled monolayer film of the chip surface and it is thus not easily accessible to the target duplex DNA. In order to more quantitatively demonstrate the modulated desorption of the input strand from the chip surface upon potential application, we have employed an input DNA strand labeled with an electrochemically active tag (i.e., methylene blue) (Figure S2). The current signal of the electrochemical tag, before and after the potential input is applied, provides a measure of the amount of input strand retained on the chip surface (Figure S3). As expected, we found negligible differences in the current signal for chips treated with applied potentials higher than $-0.4 \mathrm{~V}$ while major suppression of the signal is observed for applied potentials lower than $-0.6 \mathrm{~V}$ (Figure S3). Of note, no electrochemical signal due to methylene blue was observed for applied potentials lower than $-1.1 \mathrm{~V}$ indicating that the input strand was completely desorbed from the chip surface under these conditions (Figure S3), an observation that is consistent with optimal activation of strand displacement reaction. A further indication of the modulated input strand desorption is also given by the cathodic current produced by the breakage of the $\mathrm{Au}-\mathrm{S}$ bond and recorded during the application of the potential. Cathodic currents different from those recorded with control chips (without the input strand) were recorded only for potentials lower than $-0.6 \mathrm{~V}$ (Figure S4).

The electronic activation of the strand displacement reaction can be also modulated by varying the density of the input strand on the chip surface. This is easily obtained by changing the concentration of input strand employed during the deposition step (see Figure 2a). Again, using methylene-blue tagged input strand it is possible to measure the actual density of the input strand on the chip surface using the reduction peak signal of methylene blue (Figure $2 b$ ). By varying the input strand concentration between 0.1 and $10 \mu \mathrm{M}$ during the deposition step we found that it is possible to modulate the amount of deposited input strand on the chip surface from 2.0 
a
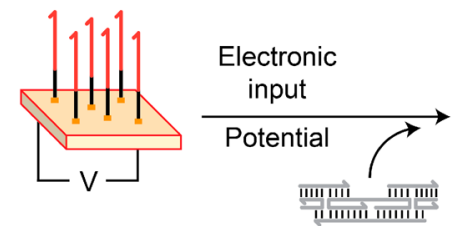

Tile

\section{b}

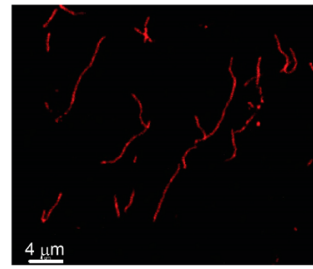

C
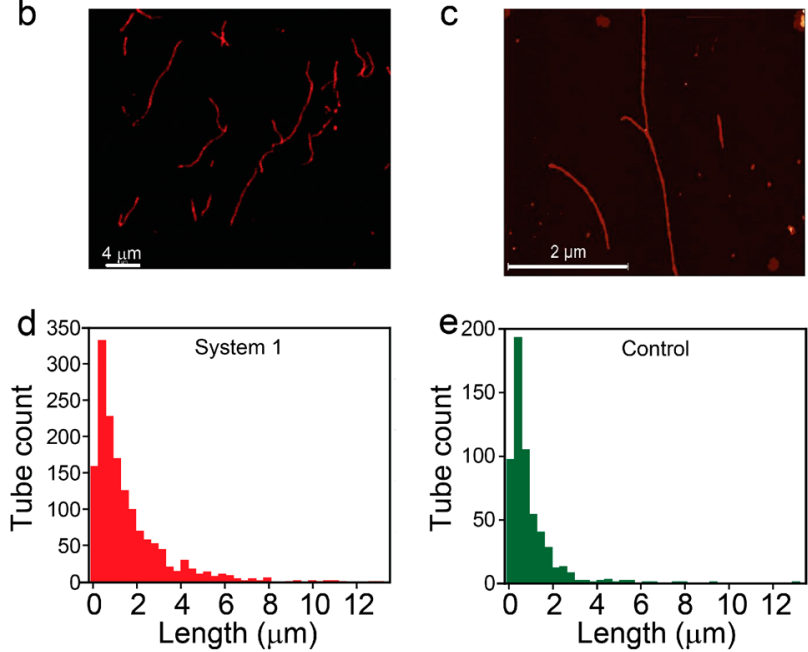

Figure 4. Remote electronic control of DNA nanostructure selfassembly. Schematics of the tile-based DNA nanotube self-assembly system triggered with electronic input (a). Confocal laser scanning microscopy (b) and AFM (c) images obtained after applying the cathodic potential to the electrode containing the deprotector strand. The length of the nanotubes formed (d) is in agreement with the length of the nanotubes formed by exogenously adding the deprotector strand (i.e., $80 \mathrm{nM}$ ) in solution (e). The experiments were performed at $25{ }^{\circ} \mathrm{C}$ in a $20 \mu \mathrm{L}$ solution of TAE $1 \times$ buffer +15 $\mathrm{mM} \mathrm{MgCl}{ }_{2} \mathrm{pH} 7.0$, containing $80 \mathrm{nM}$ of the protected tile. The concentration of the deprotector used during the deposition step was $10 \mu \mathrm{M}$ and a fixed applied potential of $-1.2 \mathrm{~V}$ vs $\mathrm{Ag} / \mathrm{AgCl}$ was applied for $10 \mathrm{~s}$. Scale bar is $4 \mu \mathrm{m}$ for confocal laser scanning microscopy image and $2 \mu \mathrm{m}$ for AFM image.

$( \pm 0.1) \times 10^{-13}$ to $3.8( \pm 0.2) \times 10^{-12} \mathrm{~mol} / \mathrm{cm}^{2}$ (Figure $\left.2 \mathrm{c}\right){ }^{61}$ This allows us to modulate strand displacement reaction through electrochemical stimuli (Figure 2d-f). We note, however, that at low densities $\left(<2.1( \pm 0.2) \times 10^{-12} \mathrm{~mol} /\right.$ $\mathrm{cm}^{2}$ ) the activation displacement reaction is within experimental error of the background signal likely because under these conditions the self-assembled monolayer on the electrode surface is not well ordered and this might affect the efficiency of electronic desorption procedure. The input strand density also offers the possibility to understand whether the electronicinduced desorption is quantitative. Indeed, we found that the strand displacement activation signal observed with the highest density chips (i.e., $3.8( \pm 0.2) \times 10^{-12} \mathrm{~mol} / \mathrm{cm}^{2}$ corresponding to a concentration of input strand in $100 \mu \mathrm{L}$ of $2.7( \pm 0.2) \mathrm{nM})$ is within experimental error of the signal achieved by exogenously adding the input strand at a $3 \mathrm{nM}$ concentration (Figure S5).

We also demonstrate that it is possible to control input strand desorption and thus strand displacement activation by varying the total period at which a fixed potential $(-1.2 \mathrm{~V}$ vs $\mathrm{Ag} / \mathrm{AgCl}$ ) is applied on the chip surface. Again, we first show the actual modulation of input strand desorption using methylene-blue-tagged DNA strand (Figure 2g,h for two a
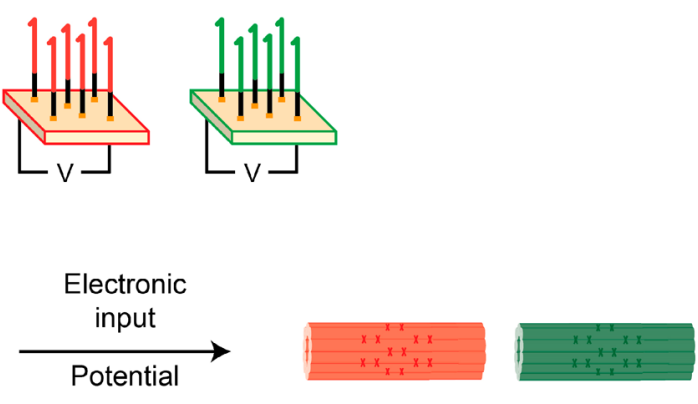

b

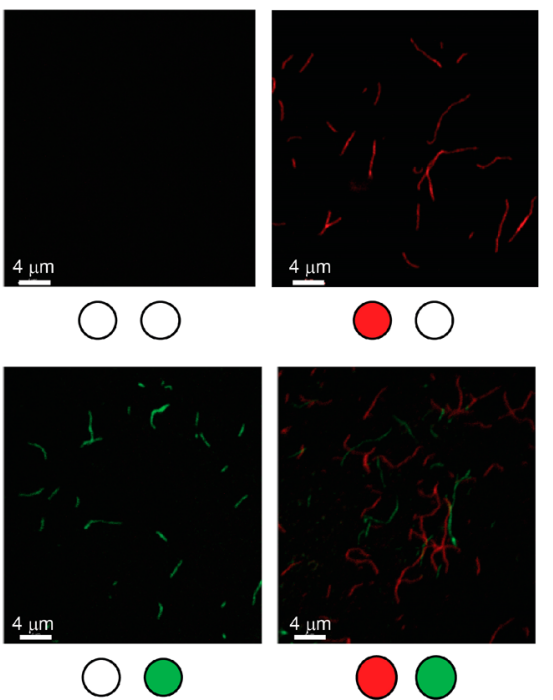

Figure 5. Orthogonal electronic control of DNA nanostructure selfassembly. By using a two- electrode chip with two different deprotector strands it is possible to orthogonally trigger self-assembly in the same solution through electronic input (a). Merged confocal laser scanning microscopy images of the two systems obtained by applying the cathodic potential in different combination (b). Filled and black circles are used to identify the electrode at which the potential was applied. The experiments were performed at $25{ }^{\circ} \mathrm{C}$ in a $20 \mu \mathrm{L}$ solution of TAE $1 \times$ buffer $+15 \mathrm{mM} \mathrm{MgCl}_{2} \mathrm{pH} 7.0$, containing $80 \mathrm{nM}$ of each protected tile. The concentration of each deprotector used during the deposition step was $10 \mu \mathrm{M}$ and a fixed applied potential of $-1.2 \mathrm{~V}$ vs $\mathrm{Ag} / \mathrm{AgCl}$ was applied for $10 \mathrm{~s}$. Scale bar is $4 \mu \mathrm{m}$.

representative periods, 6 and $30 \mathrm{~s}$ and Figure S6) and the consistent modulation of strand displacement activation between 20 and $100 \%$ (Figure 2i-1).

Electronic-induced desorption of the input strand is reversible. In the absence of the reporter complex in solution and under open-circuit condition the input strand, as expected, spontaneously readsorb on the chip surface. To demonstrate this, we have applied a cathodic potential $(-1.2 \mathrm{~V}$ for $30 \mathrm{~s})$ and then waited different periods before the addition of the reporter complex in solution. After $60 \mathrm{~min}$, a significant reduction in the strand displacement efficiency (i.e., 52\%) is observed thus suggesting that a portion of the thiolated input strand reabsorb on the chip surface under open-circuit conditions (Figure S7).

Electronic activation allows the orthogonal remote control of different strand displacement reactions in the same solution. To demonstrate this we have employed, together with the above characterized system (Figure 3a), other two additional input strands, each targeting a specific duplex DNA labeled with a different fluorophore/quencher pair (Figure $3 b, c)$. Both these 
additional systems can be controlled by electronic inputs (Figures S8 and 9), period of potential application (Figures S10 and 11) and input strand surface density (Figures S12 and 13) as the previously characterized system. To demonstrate orthogonal electronic activation of strand displacement reactions we have deposited each input strand on the surface of a three-electrode disposable chip (Figure 3d). By selectively applying the input potential on a single electrode, it is possible to release in solution the desired input strand in a controllable way and activate only a selected strand displacement reaction without significant cross-reactivity (Figure $3 \mathrm{e}, \mathrm{f}$ ).

Electronic inputs can be further used to remotely control the self-assembly of DNA-based nanostructures. To demonstrate this, we have employed a classic DNA tile self-assembly process that, through a strand displacement reaction between a protected nonreactive DNA tile and a deprotector DNA strand, yields DNA structures with nanotube shape in a controlled and isothermal way. ${ }^{5,27,28}$ By depositing the deprotector strand on the chip surface we can remotely control nanotubes selfassembly through electronic input (Figure 4a). Confocal laser scanning microscopy (Figures $4 \mathrm{~b}$ and S14) and AFM images (Figure 4c and S15) confirm that tiles self-assemble only in the presence of the applied input potential, whereas no assembly is observed over the same reaction time without applied potential (Figures S14 and S15). Tile assembly largely yields tubular structures according to fluorescence microscopy and AFM images. Moreover, statistical analysis shows that the length and yield of nanotubes formed upon electronic input (average length $=2 \mu \mathrm{m}$ and yield $=18 \pm 10 \%)$ is comparable to those of the control system achieved by exogenously adding the deprotector strand $(80 \mathrm{nM})$ to the same solution of protected tiles (average length $=2 \mu \mathrm{m}$ and yield $=20 \pm 10 \%$ ) (Figure $4 d, e)$.

Also in this case it is possible to orthogonally control the selfassembly of different nanostructures by using a multielectrode chip. We have demonstrated this by employing two different DNA-based tiles triggered by two different deprotector strands (Figure 5a). By depositing each deprotector onto a different surface of a two-electrode chip and by selectively applying the electronic input on a single electrode, we can remotely and orthogonally control the assembly of two different structures in the same solution with no cross-reactivity (Figures 5b and S16).

Here we have demonstrated a strategy to remotely control DNA strand displacement reactions and DNA nanostructure self-assembly using electronic inputs. To do this we have applied cathodic potentials to the surface of disposable chip gold electrodes where input DNA strands were absorbed. For the controlled release of the DNA strand in solution, we employed a well-known approach that has been recently demonstrated to control the density of DNA monolayers on gold surfaces to improve the signaling of DNA-based sensors. $^{56,58,60,61}$ To the best of our knowledge, this is the first time that this approach is used to control nanoscale systems in solution. The demonstration that electronic inputs applied on a heterogeneous surface can be employed to remotely control reactions and nanoscale structures assembly in solution represents an important advancement that might open the doors to new application of electrochemistry in the field of nanotechnology.

The approach we propose here is versatile and specific and allows us to control multiple DNA strand displacement reactions in the same solution in an orthogonal way. Moreover, we demonstrate that the approach can be easily modulated by varying the applied potential, time of applied input, and density of the input strand on the chip surface. The approach also allows us to control nanostructure self-assembly in a remote and versatile way without the need of exogenous addition of reagents.

Because of the low-cost, possible miniaturization, and massproduction of the electrode chips and portability of equipment, electrochemistry represents a very versatile and convenient tool that can find different applications in clinical settings. For example, the possibility to produce ingestible electronic medical devices for both sensing and drug-delivery purposes that can be controlled inside the body through wireless communication has been recently demonstrated. ${ }^{62,63}$ Furthermore, because in the past decade several innovative DNA-based nanodevices and nanostructures have been proposed for different clinical applications, ${ }^{64,65}$ the possibility demonstrated in this work to regulate DNA-based reactions and nanostructures through electronic stimuli might open the future to new routes to in in vivo monitoring and smart drug delivery.

\section{ASSOCIATED CONTENT}

\section{Supporting Information}

The Supporting Information is available free of charge on the ACS Publications website at DOI: 10.1021/acs.nanolett.8b00179.

Supporting methods, figures (PDF)

\section{AUTHOR INFORMATION}

\section{Corresponding Author}

*E-mail: francesco.ricci@uniroma2.it.

ORCID $\odot$

Francesco Ricci: 0000-0003-4941-8646

Author Contributions

${ }^{\S}$ A.A. and E.D.G. contributed equally.

Notes

The authors declare no competing financial interest.

\section{ACKNOWLEDGMENTS}

This work was in part supported by Associazione Italiana per la Ricerca sul Cancro, AIRC (Project No. 14420) (F.R.), by the European Research Council, ERC (Project No. 336493) (F.R.), by the Research and Innovation Staff Exchange (RISE) project (F.R.).

\section{REFERENCES}

(1) Kopperger, E.; Pirzer, T.; Simmel, F. C. Nano Lett. 2015, 15, 2693-2699.

(2) Aldaye, F. A.; Palmer, A. L.; Sleiman, H. F. Science 2008, 321, 1795-1799.

(3) Li, J.; Zheng, C.; Cansiz, S.; Wu, C.; Xu, J.; Cui, C.; Liu, Y.; Hou, W.; Wang, Y.; Zhang, L.; Teng, I.-T.; Yang, H.-H.; Tan, W. J. Am. Chem. Soc. 2015, 137, 1412-1415.

(4) Meng, W.; Muscat, R. A.; McKee, M. L.; Milnes, P. J.; El-Sagheer, A. H.; Bath, J.; Davis, B. G.; Brown, T.; O’Reilly, R. K.; Turberfield, A. J. Nat. Chem. 2016, 8, 542-548.

(5) Pinheiro, A. V.; Han, D.; Shih, W. M.; Yan, H. Nat. Nanotechnol. 2011, 6, 763-772.

(6) Simmel, F. C. Nat. Mater. 2017, 16, 974-976.

(7) Zhu, G.; Hu, R.; Zhao, Z.; Chen, Z.; Zhang, X.; Tan, W. J. Am. Chem. Soc. 2013, 135, 16438-16445.

(8) Sprengel, A.; Lill, P.; Stegemann, P.; Bravo-Rodriguez, K.; Schonewei $\beta$, E. C.; Merdanovic, M.; Gudnason, D.; Aznauryan, M.; Gamrad, L.; Barcikowski, S.; Sanchez-Garcia, E.; Birkedal, V.; 
Gatsogiannis, C.; Ehrmann, M.; Saccà, B. Nat. Commun. 2017, 8, 14472.

(9) Seeman, N. C.; Sleiman, H. F. Nat. Rev. Mater. 2017, 3, 17068.

(10) Rothemund, P. W. K.; Andersen, E. S. Nature 2012, 485, 584585 .

(11) Hamblin, G. D.; Hariri, A. A.; Carneiro, K. M.; Lau, K. L.; Cosa, G.; Sleiman, H. F. ACS Nano 2013, 7, 3022-3028.

(12) Andersen, E. S.; Dong, M.; Nielsen, M. M.; Jahn, K.; Subramani, R.; Mamdouh, W.; Golas, M. M.; Sander, B.; Stark, H.; Oliveira, C. L.; Pedersen, J. S.; Birkedal, V.; Besenbacher, F.; Gothelf, K. V.; Kjems, J. Nature 2009, 459, 73-76.

(13) Maier, A. M.; Bae, W.; Schiffels, D.; Emmerig, J. F.; Schiff, M.; Liedl, T. ACS Nano 2017, 11, 1301-1306.

(14) Ke, Y.; Ong, L. L.; Shih, W. M.; Yin, P. Science 2012, 338, 11771183.

(15) Benson, E.; Mohammed, A.; Gardell, J.; Masich, S.; Czeizler, E.; Orponen, P.; Hogberg, B. Nature 2015, 523, 441-444.

(16) Bujold, K. E.; Hsu, J. C. C.; Sleiman, H. F. J. Am. Chem. Soc. 2016, 138, 14030-14038.

(17) Tørring, T.; Voigt, N. V.; Nangreave, J.; Yan, H.; Gothelf, K. V. Chem. Soc. Rev. 2011, 40, 5636-5646.

(18) Praetorius, F.; Dietz, H. Science 2017, 355, eaam5488.

(19) Douglas, S. M.; Dietz, H.; Liedl, T.; Hogberg, B.; Graf, F.; Shih, W. M. Nature 2009, 459, 414-418.

(20) Grossi, G.; Jepsen, M. D. E.; Kjems, J.; Andersen, E. S. Nat. Commun. 2017, 8, 2-8.

(21) Kuzyk, A.; Urban, M.; Idili, A.; Ricci, F.; Liu, N. Science Advances 2017, 3, e1602803.

(22) Kahn, J. S.; Hu, Y.; Willner, I. Acc. Chem. Res. 2017, 50, 680690.

(23) List, J.; Falgenhauer, E.; Kopperger, E.; Pardatscher, G.; Simmel,

F. C. Nat. Commun. 2016, 7, 12414.

(24) Seelig, G.; Soloveichik, D.; Zhang, D. Y.; Winfree, E. Science 2006, 314, 1585-1588.

(25) Zhang, D. Y.; Seelig, G. Nat. Chem. 2011, 3, 103-113.

(26) Zhang, D. Y.; Winfree, E. J. Am. Chem. Soc. 2009, 131, 1730317314.

(27) Amodio, A.; Adedeji, A. F.; Castronovo, M.; Franco, E.; Ricci, F. J. Am. Chem. Soc. 2016, 138, 12735-12738.

(28) Zhang, D. Y.; Hariadi, R. F.; Choi, H. M. T.; Winfree, E. Nat. Commun. 2013, 4, 1965.

(29) Chen, H.; Weng, T. W.; Riccitelli, M. M.; Cui, Y.; Irudayaraj, J.; Choi, J. H. J. Am. Chem. Soc. 2014, 136, 6995-7005.

(30) (a) Baker, B. A.; Mahmoudabadi, G.; Milam, V. T. Soft Matter 2013, 9, 11160-11172. (b) Huang, F.; You, M.; Han, D.; Xiong, X.; Liang, H.; Tan, W. J. Am. Chem. Soc. 2013, 135, 7967-7973.

(31) Rahbani, J. F.; Hariri, A. A.; Cosa, G.; Sleiman, H. F. ACS Nano 2015, 9, 11898-11908.

(32) Green, L. N.; Subramanian, H. K. K.; Mardanlou, V.; Kim, J.; Hariadi, R. F.; Franco, E. J. Biomol. Struct. Dyn. 2015, 33, 46-47.

(33) Green, L.; Amodio, A.; Subramanian, H. K. K.; Ricci, F.; Franco, E. Nano Lett. 2017, 17, 7283-728.

(34) Wickham, S. F.; Bath, J.; Katsuda, Y.; Endo, M.; Hidaka, K.; Sugiyama, H.; Turberfield, A. J. Nat. Nanotechnol. 2012, 7, 169-173.

(35) Liu, M.; Hejesen, C.; Yang, Y.; Woodbury, N. W.; Gothelf, K.;

Liu, Y.; Yan, H.; et al. Nat. Commun. 2013, 4, 2127.

(36) Genot, A. J.; Zhang, D. Y.; Bath, J.; Turberfield, A. J. J. Am. Chem. Soc. 2011, 133, 2177-2182.

(37) Amodio, A.; Zhao, B.; Porchetta, A.; Idili, A.; Castronovo, M.; Fan, C.; Ricci, F. J. Am. Chem. Soc. 2014, 136, 16469-16472.

(38) Liu, Z.; Li, Y.; Tian, C.; Mao, C. Biomacromolecules 2013, 14, $1711-1714$.

(39) Hu, Y.; Ren, J.; Lu, C. H.; Willner, I. Nano Lett. 2016, 16, 45904594.

(40) Li, T.; Famulok, M. J. Am. Chem. Soc. 2013, 135, 1593-1599.

(41) Han, X.; Zhou, Z.; Yang, F.; Deng, Z. J. J. Am. Chem. Soc. 2008, 130, 14414-14415.

(42) Pei, H.; Liang, L.; Yao, G.; Li, J.; Huang, Q.; Fan, C. Angew. Chem. 2012, 124, 9154-9158.
(43) Liu, Z.; Tian, C.; Yu, J.; Li, Y.; Jiang, W.; Mao, C. J. Am. Chem. Soc. 2015, 137, 1730-1733.

(44) Liao, W. C.; Lu, C. H.; Hartmann, R.; Wang, F.; Sohn, Y. S.; Parak, W. J.; Willner, I. ACS Nano 2015, 9, 9078-9086.

(45) Yang, H.; Liu, H.; Kang, H.; Tan, W. J. Am. Chem. Soc. 2008, 130, 6320-6321.

(46) Feng, L.; Lyu, Z.; Offenhäusser, A.; Mayer, D. Angew. Chem., Int. Ed. 2015, 54, 7693-7697.

(47) Sannohe, Y.; Endo, M.; Katsuda, Y.; Hidaka, K.; Sugiyama, H. J. Am. Chem. Soc. 2010, 132, 16311-16313.

(48) Gareau, D.; Desrosiers, A.; Vallee-Belisle, A. Nano Lett. 2016, 16, 3976-3981.

(49) Yang, Y.; Endo, M.; Hidaka, K.; Sugiyama, H. J. Am. Chem. Soc. 2012, 134, 20645-20653.

(50) Kohman, R. E.; Cha, S. S.; Man, H.-Y.; Han, X. Nano Lett. 2016, 16, 2781-2785.

(51) Kohman, R. E.; Han, X. Chem. Commun. 2015, 51, 5747-5750.

(52) Kuzyk, A.; Yang, Y.; Duan, X.; Stoll, S.; Govorov, A. O.; Sugiyama, H.; Endo, M.; Liu, N. Nat. Commun. 2016, 7, 10591.

(53) Asanuma, H.; Liang, X.; Nishioka, H.; Matsunaga, D.; Liu, M.; Komiyama, M. Nat. Protoc. 2007, 2, 203-212.

(54) Takeishi, S.; Rant, U.; Fujiwara, T.; Buchholz, K.; Usuki, T.; Arinaga, K.; Takemoto, K.; Yamaguchi, Y.; Tornow, M.; Fujita, S.; Abstreiter, G.; Yokoyama, N. J. Chem. Phys. 2004, 120, 5501-5504.

(55) Walti, C.; Wirtz, R.; Germishuizen, W. A.; Bailey, D. M. D.; Pepper, M.; Middelberg, A. P. J.; Davies, A. G. Langmuir 2003, 19, 981-984.

(56) Wang, J.; Rivas, G.; Jiang, M.; Zhang, X. Langmuir 1999, 15, 6541-6545.

(57) Honarvarfard, E.; Gamella, M.; Guz, N.; Katz, E. Electroanalysis 2017, 29, 324-329.

(58) Murphy, J. N.; Cheng, A. K.; Yu, H. Z.; Bizzotto, D. J. Am. Chem. Soc. 2009, 131, 4042-4050.

(59) Shoseyov, O.; Levy, I. NanoBioTechnology: Bioinspired Devices and Materials of the Future; Springer Science \& Business Media, Totowa, NJ, 2008.

(60) Sánchez-Pomales, G.; Santiago-Rodríguez, L.; Rivera-Vélez, N. E.; Cabrera, C. R. J. Electroanal. Chem. 2007, 611, 80-86.

(61) Ricci, F.; Lai, R. Y.; Heeger, A. J.; Plaxco, K. W.; Sumner, J. J. Langmuir 2007, 23, 6827-6834.

(62) van der Schaar, P. J.; Dijksman, J. F.; Broekhuizen-de Gast, H.; Shimizu, J.; van Lelyveld, N.; Zou, H.; Iordanov, V.; Wanke, C.; Siersema, P. D. Gastr. End. 2013, 78, 520-528.

(63) Nadeau, P.; El-Damak, D.; Glettig, D.; Kong, Y. L.; Mo, S.; Cleveland, C.; Booth, L.; Roxhed, N.; Langer, R.; Chandrakasan, A. P.; Traverso, G. Nat. Biom. Eng. 2017, 1, 0022.

(64) Linko, V.; Ora, A.; Kostiainen, M. A. Trends Biotechnol. 2015, 33, 586-594.

(65) Chen, Y. J.; Groves, B.; Muscat, R. A.; Seelig, G. Nat. Nanotechnol. 2015, 10, 748-760. 